\title{
A comparative critical study on regulatory instruments to further large-scale desalination and energy mix diversification through the symbiotic use of selected non-conventional renewable energies
}

\author{
R. M. Plaza \\ Research Directorate, University of Chile (UCH), Chile
}

\begin{abstract}
The paper delves into regulatory challenges posed by the idea of a large-scale cooperative relationship between non-conventional renewable energy sources (NCRES). It conducts a regulatory study of a prospective symbiotic relationship between hydrokinetic and solar power and their combined potential to further energy matrix diversification, GHGs emissions abatement, and large-scale seawater desalination as a means to the ultimate deployment of bioenergy industry in desertified zones.
\end{abstract}

Keywords: hydrokinetic energy, solar power, bioenergy, desalination, renewables, legal framework.

\section{Problems and research question}

In the aftermath of the Kyoto Protocol, several international cooperation mechanisms have been developed to tackle the climate change problem (for example, 1972 Stockholm, 1992 Rio and Rio+20 Conferences, 1982 Nairobi and 2002 Johannesburg Summits). The UN Environment Programme (UNEP) has stated that desertification results "mainly from adverse human impact" whilst the UN Convention to Combat Desertification (UNCCD) defined desertification as "land degradation in arid, semi-arid, and dry sub-humid areas resulting from climatic variations and human activities". In turn, the availability of conventional energy sources is still largely dependent on geographical location and other physical parameters. In contrast, increasing technological capacity to harness the 
energy potential of worldwide-spread non-conventional renewable sources tends to progressively level the field of countries' available energy options.

Although there are international frameworks and some regional instruments in combat against desertification, in part because the linkage between energy and the water-cycle has been consistently obliterated and partly because renewable energy source (RES) integration is still insufficient, there are neither international nor domestic regulatory instruments promoting a combined, symbiotic use of renewable energy technologies (RETs) feeding water desalination plants, thus, raising the critical question of what - to that end would a suitable regulatory framework look like.

\section{An innovative solution: the research thesis}

Water desalination technologies such as MSF evaporation and reverse osmosis (RO) processes have proven themselves to be effective in water-stressed zones such as the Gulf Cooperation Council countries (GCC). In Saudi Arabia, for instance, the use of desalination techniques dates back to the 1970s, where fossil fuels are still used as a backup for CSP desalination plants. However, this is not the case in many other dry zones with limited or no endowment of fossil fuels.

The thesis advances the combined symbiotic use of a particular mix of energy sources chosen by threefold criteria: firstly, they must be standard technologies; secondly, they must be capable of producing clean energy on a large-scale to feed industrial processes whilst reducing GHG emissions; and, finally, they must have enough supplementary technical features to interplay virtuously. Accordingly, the selected RETs are: hydrokinetic energy, solar power and bioenergy. Since renewables still cannot serve as sole drivers for large-scale desalination plants without resorting to conventional backup energy, this paper advances the combined use of ocean energy and PV/CSP for feeding desalination plants. These two sources enjoy supplementary features. Whilst PV/CSP can supply base-load power, tidal energy can do it as a backup, and vice versa. Further, in the case of need both can join in. Furthermore, salts and chemicals are by-products of desalination, which might serve as raw materials for the CSP industry whilst its main product: water is to be used for municipal consumption, to replenish aquifers, reclaim drylands and, eventually, allow agricultural uses such as reforestation, and bioenergy-related industries which might transform the models of sustainable development for desertified lands.

The paper uses a comparative legal methodology to look at the RET selection, focusing each time on three critical problems to the long-term, large-scale promotion and effective implementation of them: (i) access conditions to the energy market, (ii) policy/regulation of NCREs, and (iii) capital financing needs for renewable energy infrastructure projects. All this is aimed at identifying and analysing in detail regulatory instruments and policy measures suitable for the prospective deployment of such RETs in high water-stressed zones. 


\section{Regulatory challenges and instruments}

\subsection{International level}

\subsubsection{Energy access}

Nearly 1.3 billion people have no access to electricity. Renewable energy can help to improve the access situation [1, p. 15]. Let us take solar power as an example: every hour the sun radiates more energy onto the Earth than the entire human population uses in one year [2], but the share of solar power in the global energy mix amounts only to one percent. Nonetheless, currently, lower costs for solar-based utility-scale systems are opening markets whether it comes down to solar PV, CSP, or solar thermal heating systems. Access conditions to the energy market are largely dependent on the availability or management of natural resources.

In regard to improving energy access, UN Decision 9/1 declares that access 'implies finding ways and means by which energy services can be delivered reliably, affordably and in an economically viable, socially acceptable and environmentally sound manner' [3]. Accordingly, as to renewable energy it encourages governments to 'develop and implement appropriate national, regional and international policies and measures to create an enabling environment for the development, utilization and distribution of renewable energy sources' and 'promote the utilization of renewable natural resources' [3].

\subsubsection{Non-conventional renewables policy and regulation}

At present, 144 countries have defined voluntary targets for renewable energy in their energy mix [4] and 138 have renewable energy support policies. Underscoring this fact, a high-level panel convened by the UN Secretary General recommended reliable and sustainable energy to be included in the Post-2015 Development Agenda [5, p. 3] and set goals to that end: to secure sustainable energy and manage natural resource assets sustainably (Goals VII and IX [5, p. 16]).

In 2011, the UN Secretary-General launched 'Sustainable Energy for All' (SE4ALL) as a global initiative that would mobilize action in support of three interlinked objectives, of which doubling the share of renewable energy in the global energy mix by 2030 is of relevance here because it originated the Global Renewable Energy Roadmap (REmap 2030) implemented and overseen by the International Renewable Energy Agency (IRENA). IRENA acknowledges, however, that achieving the goal of doubling the renewable energy share by 2030 relies heavily on the success in replacing the traditional use of biomass almost entirely (mainly for heating and transportation). The hybrid symbiotic use of renewables advanced by this paper relates to environments in which biomass is negligible or simply not present and it claims the potential for land reclamation, reforestation, and ultimately biomass generation capacity.

One of the latest efforts in identifying what policy makers can do to accelerate renewable energy deployment has been led by IRENA. Indeed, through REmap 2030, the global hub for renewable energy cooperation and information 
exchange has defined five key areas for national policy action on the matter: (i) establishing transition pathways for renewable energy, (ii) creating an enabling business environment, (iii) integrating renewable energy, (iv) managing knowledge, and (v) unleashing innovation [1, p. 128].

\subsubsection{Energy projects capital finance}

International Law practice has galvanized the idea that the choice and implementation of policies on how to achieve energy for sustainable development basically rest upon governments. Naturally, the target of every policy is to be put into action whether it is performed by the State itself, the private sector or a combination of them. In any case and not to mention further stages of development, execution and operation, all implementing actions of energy infrastructure projects require financing and a correct estimation of capital financing needs is crucial, since financing options and infrastructure investments made at present will lock-in future generation capacity and energy use. Decision 9/1 includes in its recommendations on renewable energy, strengthening financial support to developing countries by making renewable energy technologies more affordable (Point 3 Recommendations on renewal energy (h) and (i) [3]). Naturally, Official Development Assistance (ODA) [6] is also an important option of external funding for sustainable development as well as the Abu Dhabi Fund for Development (ADFD) which provides concessionary loans and grants on behalf of the Abu Dhabi government to developing countries and executes projects as well [7].

It is worth recalling that in appraising a non-conventional energy project, substitution costs are a key element. A proper way to address the costs associated with substituting conventional sources by non-conventional ones should vary depending on whether the project is carried on by governments or private stakeholders. In the former situation, there is no question about the need for excluding energy taxes and subsidies as well as about using a proper standard discount rate when needed for project comparison across countries and costbenefit analysis. As to the latter, in contrast, said items of energy taxes, subsidies and capital costs must be included in national prices as additional costs e.g. transmission costs, lines, transformers, substations, etc. to obtain a localised cost.

Along with identifying areas for policy action as seen in the previous section, IRENA also supports project developers facilitating the securement of funds via an innovative tool recently released: Project Navigator - an online platform designed to facilitate renewable energy projects worldwide (launched on April 22nd 2015). Through this, RETs project proposals are standardized in such a way that funding institutions can better assess their bankability. The Navigator includes project development guidelines, which are a 'compendium of legal, environmental, economic and organisational recommendations' [8] addressing financial challenges that might be encountered during the project's development process. The tool also comprises technical concept guidelines focused on technology-related specifics to be addressed by developers. 


\subsection{Domestic level}

There are a number of ways in which energy issues can be addressed, but in a given country it depends largely on the domestic energy situation, the structure of their economies and the way they have pursued similar development policies as to energy in the past. In this section we will look again at the three critical problems to effective implementation of RETs: access conditions, financing, and regulation from a domestic point of view and each will be analysed in connection with one of our threesome selection of non-conventional RETs. We will look at pioneer countries which can provide useful policy lessons and strategies on RET deployment.

\subsubsection{Energy market access and ocean energy}

Ocean energy potential is as massive [9] as some facts about it are impressive. Firstly, technological ways to harness it are wide and varied (wave, tidal, instream, etc) [9]. Secondly, some of these are in industrial use and date back to 1966 with outstanding economic performance (for example, La Rance (France), Lake Sihwa (South Korea), and SeaGen (N. Ireland).) Last but not least, notwithstanding harnessing efforts throughout all since, ocean power represents only $527 \mathrm{MW}$ of the global generation capacity [11]. In this realm, models to look at internationally are France, South Korea and particularly the UK, whose consistent and transparent regulatory framework on permits and environmental assessment has become paramount and highly attractive for offshore hydrokinetic energy projects.

The starting point for hydrokinetic energy projects, irrespective of the technology involved is to secure coastal areas to install facilities and perform their activities. In the UK, the Crown Estate holds property rights for submerged areas in public trust [12] and, accordingly, since 2001 it has called for bids to lease and awarded offshore areas for renewable energy projects, largely windfarms. Over time, different policy schemes have been introduced to further ocean energy farms. The 2006 Wave and Tidal Stream Energy Demonstration Scheme, for instance, encouraged pre-commercial tests for hydrokinetic plants through capital grants and revenue supports, exempting developers from climate change levies, and allowing them to sell renewable obligation credits. These easy-access policy instruments were supplemented with regulatory advancements, such as the Renewable Energy Zone (REZ) declaration process inaugurated by the 2004 Energy Act [13].

However, not all has been straightforward and easy. At the beginning, the approval process for offshore renewable energy projects, mostly wind but also hydrokinetic ones was highly criticized for being regulated under several pieces of legislation which, as a result, discouraged many developers forced to undergo separate approval and consent processes subject to correspondingly several authorities. In response, the UK government launched the so-called 'one-stop shopping' approach requiring bidders to obtain a single consent from the authority to carry out a renewable energy project. The Energy Act 2008 also made provision in relation to electricity generated from renewable sources in its Part 2 which deals with renewables obligation, feed-in tariffs for small-scale 
generation facilities, and, most importantly, with offshore electricity transmission in regard to tender exercises [14].

In sum, the regulatory framework in which hydrokinetic systems will operate might vary substantially from country to country and it is crucial for making the deployment of this technology effective and opening access to the market.

\subsubsection{Policy and regulation on solar power}

Despite Earth having extended areas with impressive ratios on direct solar radiation, solar technologies deployment still lags behind other RES at global level and only very recently it has made its debut into the energy market as a cost-efficient option for large-scale supply, arguably thanks to Germany's lead policy role.

In 2000, the German Renewable Energy Sources Act (EEG) was enacted to further sustainable development of energy supply and RETs. The concept of feed-in tariffs (FiT) became the cornerstone of the German energy policy. Although amendments to the EEG are actively discussed at present [15], the German energy package based on a technology-specific FiT scheme on a degressive scale, long contract periods and guaranteed access to the grid has been supplemented with price-based investment incentives and robust loan programmes to support research and development. The package has led to swift upscaling deployment of renewables, most notably the solar PV manufacturing industry which contributed to greatly reduce PV panel prices and even to exceed government targets on the renewables sector's generation and production capacity.

For some years now, CSP technology has been successfully tested in the United Arab Emirates, China, India, the USA and Spain. The cost of ESCsourced power is still greater than that of wind or fossil fuels-sourced power, interestingly though, it is cheaper than producing photovoltaic energy [16]. However, there are still important issues with CSP mostly dealing with water issues such as reduced steam-cycle net efficiency, CSP hydro-footprint and water alternative uses [17]. These technical though critical issues can be illustrated pointing out that water required by thermo coal-fired plants per $\mathrm{MW} / \mathrm{hr}$ is nearly 50 percent less than that required by CSP facilities and 300 percent less than natural gas-fired combined cycle plants [18].

\subsubsection{Capital financing needs and biomass}

Bioenergy or biomass is energy coming from organic matter. Wood is certainly the largest and most common source of biomass, but there are many others capable of being used nowadays, particularly certain crops and residues from agriculture, not to mention the organic component of municipal and industrial wastes. The small-scale use of biomass in farmer-based collection systems for agricultural/livestock-feeding purposes has been traditional in rural areas largely due to the lack of access to more sophisticated energy technologies. Over time and depending on the availability of financing options, small-scale biomassbased systems will have to compete with other energy sources e.g. agricultural residue gasification systems, bioethanol, and biomass-based power plants, namely, modern forms of biomass. 
Studies point to the fact that modern biomass should play a key role in doubling the global renewable energy share by 2030 [19, p. 60] through fossil fuel and traditional biomass-use substitution. Most importantly, there is a number of drought-tolerant crops capable of thriving in the desert sun (argan and olive trees) or less than ideal conditions using drip irrigation techniques or highvalue unconventional crops on seemingly valueless land such as algae or genetically modified aquaculture products capable of being fed with brackish or low-quality water and used as feedstock for either biofuels or neutraceuticals. In this area, studies are being conducted with promising results in Israel by the BenGurion University and the Weizmann Institute as well as by the King Fahd University in Saudi Arabia.

In China, for instance, the enactment of the Renewable Energy Law (MOFCOM) in 2005 gave birth to and supports a wide range of policy measures and strategies implemented on a long-term basis including planning and targets for biofuels (e.g. bioethanol) and biomass power generation capacity amongst others; technology standardisation, technology demonstration through pilot plants, subsidies, preferential taxes or tax exemptions, low-interest loans, mandatory consumption of liquid biofuels, and financial support for research and development as well as for training and local technical support. Consequently, the financial support has increased from USD 47 million in 2002 to USD 760 million in 2011 [19, p. 29].

\section{Case studies}

This section looks closely at Saudi Arabia's long experience on desalination, which is currently transitioning to a mix of conventional and non-conventional energy sources. It then moves on to analyse some relevant aspects of the Colombian experience, to finish up applying previous lessons to Chile.

\subsection{Saudi Arabia}

Saudi Arabia's installed power generation capacity stands at 45,000 MW, of which 45 percent is produced from natural gas and the rest comes from liquid fossil fuels. In addition, the Saudi energy mix is heavily influenced by a serious opportunity-cost dilemma: when international oil prices are high, it is economically convenient for Saudi Arabia to try to introduce renewables for supplying domestic power demand and so freeing exportable crude-oil.

Indeed, oil-producers have been diverting most of the crude production to international trade because they privilege exporting to maximize revenues. As a result, there is a pricing gap between international and domestic markets for crude oil, meaning that for each barrel diverted to local consumption there is an important loss in export revenues. In turn, export revenues have an impact on the energy mix configuration since a relevant share thereof is destined for research and development (R\&D) as well as to RETs' integration and application: desalination technologies amongst them. Such a diverting process has forced Saudis to allocate natural gas to feed the petrochemical industry in order to meet 
the domestic power demand. However, according to Saudi National Development Plans there is not enough to meet its economy's power needs. This is ultimately the reason why Saudi Arabia is embarked on a national priority project consisting of fully transitioning to renewables and, for that matter, delivering the whole country's freshwater demand through solar-powered desalination plants by 2019 .

The so-called King Abdullah Initiative for Solar Water Desalination is a government programme announced in 2010, aimed at desalinating seawater at a low-cost through solar energy. The programme has three phases: the first consisted of building the Al-Khafji solar/desalinating complex in operation since 2013 and sited alongside the homonymous coastal city. The solar power plant of $10 \mathrm{MW}$ of installed capacity uses ultra-high concentrator photovoltaic technology to power a RO desalination plant capable of producing $30,000 \mathrm{~m}^{3} /$ day of drinkable water. The second phase consists of building a much larger solarpowered desalination plant able to deliver $300,000 \mathrm{~m}^{3} /$ day. The third and final phase aims at implementing the initiative throughout the country as well as commercializing the technology worldwide. Bearing in mind that fossil fuelfired power and desalination plants consume around 1.5 million barrels of oil per day, thus, underscoring the aforementioned Saudi trading dilemma, it is perfectly understandable that the King Abdullah initiative seeks to operate at renewables' lowest cost possible.

In sum, recalling the abundance of conventional fuels it is not surprising that, in spite of having the bulk of its population distributed alongside coastal areas, Saudi Arabia had never seriously considered hydrokinetic power as backup power for its 97 existing desalination plants [20]. By contrast, for countries with a similar configuration of population distribution and high water-stressed zones like Yemen, Peru, northern Chile, India, or Sudan to name a few, although less endowed with other natural resources, the possibility of powering desalination plants through harnessing ocean energy becomes paramount.

\subsection{Colombia}

It might seem peculiar to refer to Colombia in a study dealing with hot spots, desertification, desalination, and NCRES for Colombia boasts one of the largest global hydropower capacities. However, we will look here at two specific aspects of the Colombian energy sector of relevance to our analysis: the investment attracting-oriented regulatory model and some features of the Regulatory Commission of Energy and Gas (RCEG) introduced by Law $1.215 / 2008$.

Colombia has a mix of partly state-owned and controlled companies operating alongside private firms, both domestic and transnational. The sector's regulatory framework is largely market-driven but comprises relevant features of government oversight and long-term energy planning to ensure electricity supply and adequate minimal infrastructure according to the National Energy Plan (NEP). Two further aspects of the Colombian power market are noteworthy: firstly, renewables are still expensive largely because the government does not provides them with general subsidies (except funds managed by the Institute of 
Planning and Promotion of Energy Solutions and the Financial Support Fund for the Electrification) or tax exemptions for ocean energy projects [21], thus, they must compete against coal, a domestic abundant resource or against natural gas as backup energy to hydropower during dry seasons. Secondly, the preference for long-term power supply contracts rather than relying on the on-the-spot market is quite understandable given the heavily hydro-influenced energy mix and wide swings of hydropower output.

Although hydrokinetic power in Colombia has a large potential [22], it is still overshadowed by other lower-cost energy sources enjoying clear leverage. The oil and gas sector is one of them, but several policy and regulatory lessons can be drawn out of it for the benefit of offshore hydrokinetic projects. Firstly, to attract foreign and domestic private investment Colombia has restructured the sector institutional framework by creating a specialised independent regulatory body responsible for setting standards and rules for licensing rounds, providing relevant information to potential stakeholders, overseeing bidding, auctioning and licensing processes, and awarding licenses and contracts. Secondly, Colombia has expanded territories under concession most notably large offshore areas but also onshore small fields. Thirdly, Colombia has revised tax regimes to stimulate businesses hence significantly cutting off royalties and revenue taxes. Finally, it has partly privatized the sector formerly state-owned company: Ecopetrol.

Finally, Law 1.215/2008 amended Law 142/1994 in regard to power generation through cogeneration processes, assigning RCEG authority to issue the requirements and technical conditions. This amendment was particularly important because it allowed cogenerators to sell surpluses to utilities and, thus, it constituted additional stimuli for transitioning to alternative energy sources.

\subsection{Chile}

Northern Chile's current mining-based economy involves intensive use of water resources. However, due to climate and geographic conditions, water is extremely scarce and neither hydro nor biomass electricity generation is possible. Nonetheless, most of the population occupies coastal areas boasting considerable wind and/or wave-power potential. The same geo-climatic reasons explain the enormous potential for solar power, whether based on photovoltaic and/or more recently CSP technology. Chile has two main power grids: the Central Interconnected System (SIC) and the Grand North Interconnected System (SING). Although a legal initiative on interconnection is long being discussed, both grids are still functionally apart. Whilst SIC's supply is mostly sourced in hydropower originated in central and southern Chile, up in the north where the bulk of the Chilean mining industry locates SING's electricity output comes in almost 82 percent from coal-based generating units, 9 percent from natural gasfired plants, and 7.5 percent from diesel, thus, making Chile's northern energy matrix 98.5 percent fossil fuels-based [23]. Chile is currently an electricity net importer and its critical energy supply situation is aggravated by significant hurdles to energy integration processes with neighboring countries. 
Aguas de Antofagasta S.A. (ADASA) is a company based in Chile's driest territory which also concentrates the bulk of most relevant and water-intensive mining activities. ADASA delivers freshwater by means of ground-level collection points and groundwater wells whose output is channeled through $1.140 \mathrm{~km}$ of pipelines to undergo a purification process in water-treatment plants. Recently, Antofagasta PLC, a holding company, has announced that it has reached an agreement to transfer the ownership of ADASA to Medellín Public Enterprises Group (EPM Group). EPM is a Colombia-based group. Given Colombian present interest to invest in the Chilean water sector it is not illfounded to envision a Saudi Arabia-Colombia joint venture for the (first stage of) combined CSP/hydrokinetic-based R/O desalination plants in northern Chile.

\section{Conclusions}

There is a strong interdependency between water and energy. The research starting question was how to take advantage of vast tracks of land affected by drought, desertification and deforestation processes, mining or other industrial activities. In response to it, the idea of a large-scale cooperative relationship between selected NCREs was advanced. Since, most regional and domestic energy networks are still almost entirely carbon- and/or hydroelectricity-based, the thesis envisaged an alternative pathway for reclaiming these lands, diversifying energy mixes and abating GHGs based on a combined cooperative use of three NCRES: hydrokinetic, solar power, and bioenergy.

The analysis was receptive to RES having supplementary features, large power generation potential and affinity to high water-stressed coastal areas in order for them to work cooperatively to achieve large-scale seawater desalination. The paper then delved into relevant policy topics dealing with access to markets, renewables' regulatory framework and energy projects financing both at an international and domestic level, and analysed three case studies: Saudi Arabia, Colombia and Chile.

The Chilean case study was a prospective example of trying out the paper's thesis. Northern Chile homes Atacama Desert not only the driest place on Earth, but also has the highest solar radiation, understandably, is unable to sustain any form of bioenergy. The bulk of its population dwells along the coast whilst industrial and mining activities take place typically inland. They are powered by burning fossil fuels and require water gathered from varied local sources facing risk of depletion. The Saudi experience on solar-powered seawater desalination and drought-tolerant crops, a tailor-made regulatory framework for deployment of offshore hydrokinetic projects inspired by the Colombian oil and gas sector, the German energy transition experience as well as some international investment schemes could lay the foundations for the first stage of a pioneer combined energy project of solar and hydrokinetic power for large-scale desalination. If successful, further stages could foster the deployment of the bioenergy industry. Such a project would, ultimately, contribute to GHG emissions abatement, energy matrix diversification, and increase the security of energy supply. 
After analyzing international and domestic rules on renewable integration, promotion and financing, the research identified policy and regulatory mechanisms having the potential to introduce a renovated paradigm of sustainable development for desertified, low-productive areas. The case studies underscored the conclusion that the increasingly balanced field of available energy options to supply power demand is critically affected by policy and/or regulatory decisions on energy matrices.

In sum, the study confirmed the suitability of a symbiotic interaction between $\mathrm{CSP} / \mathrm{PV}$ and hydrokinetic power generation facilities sited on high waterstressed zones as well as their combined advantages, potential for large-scale seawater desalination and further deployment of the bioenergy industry.

\section{References}

[1] International Renewable Energy Agency, A Renewable Energy Roadmap (2014).

[2] At: www.americanenergyindependence.com (12.03.2015).

[3] $9^{\text {th }}$ Session of the UN Commission for Sustainable Development. E/CN.17/2001/19, 2001 Decision 9/1, point 1.12.

[4] Renewable Energy Policy Network for the 21st Century, Renewables 2014 Global Status Report. Key findings 2014 (2015).

[5] Report of the High-Level Panel of Eminent Persons on the Post-2015 Development Agenda, A New Global Partnership: Eradicate Poverty and Transform Economies through Sustainable Development (2013) p. 3.

[6] OECD, Glossary of Statistical Terms. Official Development Assistance.

[7] Abu Dhabi Fund for Development. At: http://www.adfd.ae (27.04.2015).

[8] https://navigator.irena.org/ (23.04.2015).

[9] Esteban, M., Leary, D., 'Current Developments and future prospects of offshore wind and ocean energy' (2012) Applied Energy 128.

[10] Griset, T., 'Harnessing the Ocean's Power: Opportunities in Renewable Ocean Energy Resources' 16 Ocean \& Coastal L.J. (2010-2011) 395, 404406.

[11] REN21, Renewables 2012 Global Status Report (Paris: REN21 Secretariat) 18.

[12] Portmann, M. Marine Renewable Energy Policy. Some US and International Perspectives Compared. (Oceanography Society, 2010), Vol. 23, Nr. 2, p. 102.

[13] 2004 Energy Act, UK. Part II, Chapter 2.

[14] 2008 Energy Act, UK. Part II, section 44.

[15] Fraunhofer ISE, 2014. Expertstatement: Wirkung des EEG - was ist die empirische Evidenz?

[16] Lanza, A. \& Verdolini, E., 'The role of R\&D in the energy sector' in Galarraga, I. (eds) Handbook of Sustainable Energy' (Elgar, 2011) p. 470, 481.

[17] Carter, N. and Campbell, R., 'Water Issues of Concentrating Solar Power Electricity in the US Southwest'. At http://circleofblue.org (01.03.2015). 
[18] International Energy Agency, Technology Roadmap Concentrating Solar Power (2010).

[19] International Renewable Energy Agency. Global Bioenergy. Supply and Demand Projections. A working paper for Remap 2030 (September 2014).

[20] Dawoud, M., Al Mulla, M., Environmental Impacts of Seawater Desalination: Arabian Gulf Case Study. Intl. Journal of Environment and Sustainability, Vol. 1 Nr. 3, pp. $22-37$ (2012), p. 24.

[21] Colombian Tax Statute, art. 207-2 provides for exemptions to the income tax.

[22] Polo, J., Rodríguez. J., Sarmiento, A., Potencial de Generación de Energía a lo largo de la costa Colombiana mediante el Uso de Corrientes Inducidas por Mareas. Engineering Magazine. Los Andes University. Bogotá (2008), p. 104.

[23] Ministerio de Energía, Agenda de Energía, Mayo 2014, p. 102. 